\title{
Crude oil price decision under considering emergency and release of strategic petroleum reserves
}

\begin{abstract}
With the development of economics, oil has an important influence on social stability. The key challenge for oil import is steady supply. However, in this article, we do not focus on this aspect but the fluctuation of crude oil price when emergency and release of strategic petroleum reserves occur. It is a very complex research in real-life environment. In this situation, case analysis is the best tool for solving this problem. Our model is formulated in such a way as to simultaneously consider new oil price breakpoints, different emergency and so on. For solving the problem, a new programming is developed. Finally, an analysis is presented to illustrate the proposed method. The results show: (1) Natural disasters have less influences on crude oil price than social conflicts. As the impact of Hurricane Katrina is 3.27, less than 4.044 of Libyan conflict, and the subsequent influence is also limited, 5 days less than 8 days of the conflict. (2) Releases of strategic petroleum reserves are effective for the reliefs of oil price fluctuations caused by emergencies, respectively $41.05,6.48$ and 5, presenting a weakening trend of stabilizing role.
\end{abstract}

Keywords: emergency; strategic petroleum reserves; crude oil price; case analysis

\section{Introduction}

In today's globally rapid development environment, oil is a major contributor to the world economy ${ }^{[1]}$, playing more and more key role on economics. However as a 
scarce and nonrenewable resource, supply and demand of crude oil is not usually matched. In view of this situation, some countries had broken out severe conflict for crude oil supply. Meanwhile, the international crude oil price is also sharply fluctuated. Hence, the reform of pricing mechanism in crude oil market is promoted. Firstly, it is changed from company pricing mode in 1960-1973 to OPEC pricing mode in 1973-1986. Finally, futures pricing in international market is widely accepted. In recent years, more and more emergencies frequently occur, for example catastrophic weather, geopolitical conflict, terrorist attack and so on. Moreover, these emergencies have largely impact on crude oil market. So, when the international crude oil price is predicted, the impact of emergency must been considered ${ }^{[2]}$.

For decreasing emergency effect, some scholars find strategic petroleum reserve is suitable to alleviating the sharp fluctuations in crude oil prices. According to this research, IEA released three strategic oil reserves for emergency (time separately was 15,30 and 30 days, the average daily release amount was 2500000,2000000 and 2000000 barrels, the proportion of the average daily consumption amount was $3.7 \%, 2.4 \%$ and $2.3 \%$ ). Three release of strategic petroleum reserves played an important role on stablizing supply and crude oil price. Meanwhile, different emergencies have diverse influences on crude oil supply and price. However, with the development of society, politics and economy, the same emergency has differently impact on this aspect. But some researchers find that the same emergency always have similar influence pattern and strength ${ }^{[3]}$. In view of this finding, historic events and past data are very important for analyzing similar emergency. And the 
establishment of strategic crude oil reserve is very necessary because it can alleviate the loss about emergency.

The main aim of this study is to improve the theory of oil price by analyzing different scenarios based on event study, get more accurate oil price analysis results closer to reality and provide effective advice for national release of strategic oil reserves. In this paper, we studies crude oil prices under considering emergency in international market by structural breakpoint method. Then, we stimultaneously analyze two emergencies, Hurricane Katrina in 2005 and Libya conflict in 2011. Finally, we deeply research the effect of emergency and release of strategic crude oil reserve on crude oil price by IEA's three releases.

\section{Literature review}

Crude oil is not only fossil raw materials, but also essential strategic energy to the economic development. It is expected that the demand for oil will continue to increase in a long time ${ }^{[4]}$. The restricting role of crude oil on economy and environment is more and more obvious, and crude oil supply and demand problem has become the focus of the society. In order to solve the contradiction between energy supply and demand, improve energy efficiency and achieve sustainable development model, many scholars have begun to study the prediction of energy ${ }^{[5]}$. Some scholars (Aydin, 2014; Say \&Yücel, 2006; Azadeh \&Tarverdian, 2007) use empirical analysis to predict energy consumption ${ }^{[6-8]}$. As CO 2 emission standard is a key constraints in the supply and demand of oil ${ }^{[9]}$, energy related $\mathrm{CO} 2$ emissions are modeled and 
predicted by scholars ${ }^{[10-12]}$. Although these studies can save oil resources to a certain extent, but cannot reverse the impact of emergencies to the energy market. In recent years, more and more scholars pay attention to crude oil price forecasting model under considering different emergencies. Many mathematical methods, for example generalized exponential predictors and gray two-step prediction, are used to forecast crude oil price. Ji and Sun (2011) ${ }^{[13]}$ divide those crude oil price forecasting model into informal model, theoretical model and simulation model (informal model has great influence on policy-making and socioeconomic development; theoretical model is the basis of research and simulation model is fit for prediction about crude oil price). Meanwhile, many factors simultaneously affect crude oil price, we must consider all aspects ${ }^{[14]}$. Fang and Li (2012) ${ }^{[15]}$ find that long-term crude oil price mainly depends on supply and demandand short-term crude oil price change is usually caused by emergency. Zhou (2004) ${ }^{[16]}$ analyzes the influence of different emergencies, such as 911 terrorist attack, on crude oil price by ARMAX model. Moreover, he also researches crude oil price under considering different stages of the emergency. Wang et al. $\left(2005^{)^{[17]}}\right.$ establish ARMA-GARCH intervention stage model for analyzing different stages of the war's influence on crude oil price. They find the stage is not significant due to the abruptness of event. Wang et al (2009) ${ }^{[18]}$ construct an ARMA-GARCH transfer function model for analyzing the influence of different emergencies on crude oil price. They investigate three effects: continued effect, immediate effect and weakening trend effect. Three emergencies are analyzed. They conclude some main results about different emergency influence on crude oil price. 
Moreover, it is useful to provide some key suggestions for the release of country' strategic crude oil reserves. For solving different emergencies, strategic petroleum reserve release is the most widely used in the world. Now, most of scholars mainly concentrate on strategic crude oil reserves' size, the time of release and efficiency. Jiao et al (2011) ${ }^{[19]}$ construct a linear programming model for analyzing the influence of different strategic crude oil reserves scale on supply disruptions and price change. The result shows that strategic crude oil reserve can effectively deal with the sharp demand and price fluctuation for emergency and reduce operation risks and economic influence. Moreover, different scale of strategic reserves may have distinct impact. Wang (2013) ${ }^{[20]}$ introduces china supply and demand pattern and import risk about crude oil. Meanwhile, he concludes that strategic crude oil reserve has a great effect on china energy security and introduces strategic crude oil reserve facility and storage condition. According to past researches, he analyzes china strategic crude oil reserve security system. Li et al (2014) ${ }^{[21]}$ studied china strategic crude oil reserve by America empirical research. Wang and Lv (2014) ${ }^{[22]}$ analyze the scale of strategic crude oil reserves. Pan et al $(2014,2012)^{[23-24]}$ research the risk and uncertain information influence on manager decision.

For crude oil imports, the risk of emergency can't be ignored. Hence, the establishment of strategic crude oil reserve is very necessary because it can alleviate the loss about emergency. Meanwhile, past relative researches rarely analyze crude oil price by emergency. Moreover, the influence of strategic crude oil reserve is usually obtained by subjective experience. This method cannot determine the extent and 
duration of influence. At the same time, it is necessary to take emergency and strategic crude oil reserve into consideration for exploring the strength and influence on crude oil price under different scenarios.

In this paper, we expand the previous researches in the following two aspects: First, based on structural breakpoint test, we determine new oil price breakpoints and analyze the stages and characteristics of fluctuations and its relationship with emergencies; Second, using event study method, we stimultaneously take emergency and strategic crude oil reserve into consideration, systematically exploring two emergencies, Hurricane Katrina in 2005 and Libya conflict in 2011, as well as IEA's three releases' influence extent and duration on crude oil price.

\section{Method}

\subsection{Structural Breakpoint Test}

We hard find out the structural breakpoints in the time series for dividing the time trend and determining the time point about structural change. Meanwhile, we research characteristics of each stage and changed step events. There are two prominent methods of breakpoint test: one is the generalized wave function, such as CUSUM, MOSUM and so on; the other is F-test, for example Chow test and Sup F test. But these methods are not fit for big data condition. Bai and Perron $(1998,2003)^{[25]}$ provided BP Multi-breakpoints structural test that is a good way for solving this problem. At the same time, it can directly detect all possible breakpoints in the sequence of events according to the procedure.

The basic principle of BP breakpoint test is to calculate multiple regression 
models with $\mathrm{m}$ breakpoints separately (it can also be $\mathrm{m}+1$ ):

$$
\begin{aligned}
& y_{t}=z_{t}^{\prime} \delta+x_{t}^{\prime} \beta_{1}+\mu_{t}, t=1,2, \cdots, T_{1} \\
& y_{t}=z_{t}^{\prime} \delta+x_{t}^{\prime} \beta_{2}+\mu_{t}, t=T_{1}+1, \cdots, T_{2} \\
& \vdots \\
& y_{t}=z_{t}^{\prime} \delta+x_{t}^{\prime} \beta_{m+1}+\mu_{t}, t=T_{m}+1, \cdots, T
\end{aligned}
$$

In the formula (1), $y_{t}$ is the value of dependent variable in time $\mathrm{t}, z_{t}(p \times 1)$ and $x_{t}(q \times 1)$ are covariance vectors, $\delta$ and $\beta_{i}$ are corresponding coefficient vectors, ${ }^{\mu}{ }_{t}$ is the random disturbance term in time $\mathrm{t}, \mathrm{T}$ is the total sample. The number of breakpoint and breakpoint date are unknown. By calculating the sum of squared residual (SSR) in the time series, we simultaneously make the level and the trend to obtain m structural changes. Meanwhile, we use BIC criteria to analyze the structure when SSR achieves global minimization. Moreover, we can obtain structural breakpoints and make confidence test.

Structural breakpoint test can be obtained by the command of breakdates that is designed by Zeileis according to formula (1) in Strucchange software package of $\mathrm{R}$ statistical software platform. Meanwhile, the relationship between independent variable and dependent variable will change $\mathrm{m}$ times. According to the minimum value of residuals in $\mathrm{m}$ times structural changes, we can determine the optimal number and time of breakpoints .At the same time, we can obtain confidence intervals for each breakpoint. The narrower confidence interval has the higher reliability.

\subsection{Analysis of Breakpoint Test Result}

The data of West Texas WTI international crude oil spot monthly prices from EIA is selected as analytical object. In order to verify the representativeness of WTI 
international crude oil price, Brent crude oil price is simultaneously used to analyze difference for breakpoint test. According to the availability of data, statistics interval is from 1987 May to 2014 December. The descriptive statistics of the data are shown in table 1. By R software, WTI BP multi- Breakpoints test results are shown in table 2.

According to the BIC criterion, 3 is the best number of breakpoints. Based on the Brent crude oil data, we find that 1999 and 2010 are only a month difference. It can be ignored. So, WTI can be used to reflect the changing trend of international crude oil price. Because breakpoint time is the last value of the interval, 1987 May to 2014 December can been divided into four stages, as shown in figure 1 .

According to the features of oil price fluctuation and the analysis of major events, four periods respectively is:

The first period (1985.5-1999.11) is oil price stable period. In this stage, the international crude oil price is relatively stable and the average crude oil price maintains at \$20. When the second oil crisis happened, the price of crude oil reached a high price of $\$ 35$ / barrel in a short term. But the price fast falls back, it does not cause a further rise in crude oil price.

The second period (1999.12-2005.5) is oil price rising period. The crude oil price begins to rise under three times reduction output of OEPC for obtaining crude oil pricing power. At last, it reached a high price of \$50 / barrel in 2005 .

The third period (2005.6-2010.10) is crude oil price rising sudden and sharp period. In this period, many emergencies take place frequently, for example 911 event 
in 2001, America' invasion of Iraq in 2003, Iran nuclear crisis, Gulf of Mexico hurricane in 2005, American subprime mortgage crisis in 2008 and so on. These emergencies push crude oil price to rise and reach the historical highest point $\$ 133.88$ / barrel in June 2008. Finally, it then plunged to $\$ 39.09$ / barrel in February 2009.

The fourth period (2010.11-2014.12) is crude oil price stable period. There are short-term shocks with an average price of $\$ 95 /$ barrel. The first wave was mainly caused by the conflict in Libya and Japan's Fukushima nuclear leak. The second wave was brought by economic sanctions in Iran. The third wave was influenced by the crisis in Ukraine. The fourth wave was caused by the deterioration of the situation in Iraq.

In general, the international crude oil price fluctuation is connected with emergencies. Moreover, the artificial geographical conflict is especially striking.

\subsection{Event Study Method}

The event study method was first proposed by Dolly in 1933, this statistical method is widely used in financial econometrics for measuring the impact of a specific event on price. By this method, we can analyze whether a specific time will affect prices, the influence degree and length of time, such as a company's stock price response to government's policy in financial field. Compared with traditional method, event study method only requires short-term sample data with clear logic and simple calculation process. At the same time, information changes in crude oil market, such as policy, supply and demand, emergencies, psychological expectations and so on, can 
respond to crude oil price fluctuation. Hence, the event study method is also suitable for the analysis of crude oil market.

Event study method mainly follows the following six steps:

(1) The occurrence time of events. This time is defined as the first time that the market gets the information of events. More accurate the time implies more reliable the test and more precise measurement of influence. In the research of time, you can select frequency such as day, month and week (day is the most widely used).

(2) Event window selection. It is the length of the period before and after the event. In general, more accurate the event in step (1) contains less useless date in the event window. At the same time, total period should be covered in the time window. About the length of time window range, there is little consensus. In actual situation, we usually take a window range of 10 days before and after the event for emergency without any prior information and take a range of 30 days before and after the event with some information in advance.

(3) The estimation window. We usually use the estimation window data to predict. If there is no emergency, data will be the trend. The estimation window can be selected before, after or in the event window. It is widely chosen before the event window. If in step (2), a 10 days event window is selected, namely $(-10,10)$, then the estimation window can be identified as $(-60,-11)$. Meanwhile, if set the event window as $(-30,30)$, then the estimation window can be $(-120,-31)$. They are quite distinct. So the estimation of the price is unbiased. Figure 2 shows an example of estimation window and event window division. 
(4) Calculate the (normal) rate of return ER. We analyze what the price rate of return is in nonoccurrence this event. There are commonly four rate of return: the average rate of return (also called the constant mean rate of return), market rate of return (such as the Shanghai Stock Exchange Composite Index), the industry rate of return (industry recognized yields) and risk adjusted rate of return (adding the part of venture gains into yields). This paper mainly uses the average rate of return.

(5)The (abnormal) rate of return AR is added, we can get the cumulative sum SAR. It means the actual rate of return every day in event window substracts the predicted normal rate of return.

(6) By test SAR and ER, we want to determine the significant level of events.

\section{Data and Analysis}

Based on above research, this section will specifically analyze the effect of two types of emergencies, including Hurricane Katrina in 2005 and Libya conflict in 2011. Meanwhile, IEA's three strategic oil reserves release are introduced from the background, the type of emergency and the results.

\subsection{The Effect of the First Energy Release}

IEA was established in 1974. It firstly use strategic oil reserves for solving supply disruption and price rising by The Gulf War in 1990. On August 2, 1900, Iraq suddenly attacked Kuwait without any warning. Because of this emergency, price of crude oil soared 58\%. On January 17, 1991, IEA launched the emergency response plan and released strategic oil reserves about 2.5 million barrels/ day in the later 15 
days. Considering the influence degree and duration, the day of the strategic oil reserves release is considered as the first day for the event. Because the release of crude oil reserves will end in a month, we take a range of 30 days before and after the event for event window. The estimation window is from July 31, 1990 to November 30, 1990 and the event window is selected from December 3, 1990 to February 28, 1991. The rate of return equation in event study is as shown:

$$
R_{t}=100 * L N\left(p_{t} / p_{t-1}\right)
$$

Where $R_{t}$ is the logarithmic return rate of time $\mathrm{t}$ in the market, and $p_{t}$ is the price in time t.

We calculate and estimate mean and variance of the rate of returns in the window, for Parameter estimation. The average value is 0.415 and the variance is 30.14 . The rate of return model can be expressed as the following equation, $e_{t}$ is normally distributed.

$$
R_{t}=0.415+{ }{ }_{t}, \quad e_{t} \sim N(0,30.14)
$$

When heteroscedasticity and autocorrelation test are carried out on the model, we find they don't obey the original assumption. It indicates that the model set is appropriate. By calculating the difference between the rate of return in event window and the average rate of return in estimation window, we can test the influence of the event. In order to accurately describe and measure the influence of emergency, we get standardized abnormal profits $a_{t}=e_{t} / \delta^{\sim} N(0,1)$, namely the square root of variance in addition to estimation window. Then calculate the $\mathrm{P}$ value using "NORMSDIST" in EXCEL. If the $\mathrm{P}$ value is less than 0.05 , the result is significant at $95 \%$ level. If the $\mathrm{P}$ 
value is less than 0.01 , the result is significant at $99 \%$ level. The event window $\mathrm{P}$ value test results are shown in table 3.

We can see from the table 3, 0 day is statistically significant at the confidence level of $95 \%$ and $99 \%$. It indicates that the influence of the first release of strategic crude oil reserves is significant for 30 days before and after the event. Combined with the results in Figure 3, we can see the abnormal income reached a large negative in the day of release. It shows that the market price of oil is very sensitive to the information of reserves release. According to the abnormal income in the later period, we can see the less times of positive abnormal return volatility and the reduced fluctuation margin. The subsequent influence on crude oil price continues at least 15 days. Hence, strategic crude oil reserve played a very good role in controlling the fluctuation of crude oil price.

\subsection{The Effect of Hurricane}

Because hurricane Katrina entered American's core oil production baseMexico Bay area, it results in more than 1/3 Oil field development, seven refineries and an American important crude oil export facility closure. Meanwhile, 95\% oil production and process were stagnated. In the second day after the accident, namely August 31st, the George W. Bush administration announced the release of strategic crude oil reserves to alleviate disaster and help crude oil processing plant for recovering production. On the fourth day after emergency, namely September 2nd, IEA announced that all 26 members in the institution would release strategic crude oil reserve to stabilize the oil market, ease the fluctuations and panic situations of oil 
market.

First, we analyze whether the disaster of hurricane had a long-term influence on crude oil price. According to our front research, we can easily find that the crude oil price will fall after the disaster. So it belongs to a pulse and short-term effect. At the same time, we study the influence degree by the event study model. This event only last for eight months. This period is relatively short. Moreover, the release of strategic crude oil reserve relieves market panic in the subsequent war. So day frequency data is selected for event study analysis. The event window is from September 25, 2005 to August 16, 2005. The average value and variance separately are 0.368 and 3.15 on the basis of approximate 10 days data. The rate of return for event study is expressed as:

$$
R_{t}=0.368+e_{t}, \quad e_{t} \sim N(0,3.15)
$$

The event window $\mathrm{P}$ value test results are shown in table 4 . At the confidence level of $95 \%,-9,0$ and 3 are significant change points. It indicates that Katrina hurricane can cause obvious rise of crude oil price. As shown in Figure 4, because of the release of USA strategic crude oil reserve in August 31, the abnormal return of two consecutive days shows negative and the rising price are suppressed. When IEA announced the release of international reserve on September 2nd, market confidence is increased. It has a greater impact on the price of crude oil than the hurricane and America's reserve release on 31 nd. Because it has a long duration, the influence of strategic reserves is not obvious when measuring a period of 15 days. So the influence duration of the second strategic oil reserves is within 15 days. 


\subsection{The Effect of Libya Conflict}

Libya Conflict broke out in February 17th, 2011. The two belligerent parties were Gaddafi and the opposition forces. Since the war broke out, the production of crude oil and gas fall sharply. Foreign crude oil companies that controlled half of Libya's oil output removed employees and stopped production. The two sides fought for crude oil and gas resources. It caused management confusion. At the same time, coastal crude oil transportation facilities faced danger of closing and destroying, part of oil refining factories and port facilities were damaged, a large number of oil and gas exports stagnated. It finally resulted in reducing daily output 1000000 barrels. Some of the oil exports got recovery due to the relief of situation. In June 23rd, IEA suddenly announced to release 2000000 barrels/day for reducing the instability in international crude oil market. With the upgrading war and the occupied capital, crude oil price continued to rise after a short-term falling. The war ended in October 23, 2011. As WTI and Brent serious inversion phenomenon in 2011, the reliability of WTI data was suspected. We select crude oil price of Brent to analyze. At the same time, because the time of conflict and strategic reserve release were far away, we must analyze two times.

First, we analyzed whether Libya conflict had a long-term impact on crude oil price. From over research, we can find that the crude oil price falled after the war. So it belongs to a pulse effect. The effect disappeared with the end of the war. It indicates a short-term effect. Second, we study the influence degree by the event study model. This event only lasted for eight months. It is relatively short. Moreover, the release of 
strategic crude oil reserve relieves market panic in the subsequent war. So day frequency data is selected for event study analysis. The estimation window is from November 24, 2010 to February 4, 2011, and the event window is from February 4, 2011 to March 8, 2011. There are 10 data before and after the event day. We calculate and estimate mean and variance of the rate of returns in the window for Parameter estimation. The average value and variance separately are 0.376 and 1.298 . The rate of return model can be expressed as the following equation, $e_{t}$ is normally distributed.

$$
R_{t}=0.376+e_{t}, \quad e_{t} \sim N(0,1.298)
$$

The event window $\mathrm{P}$ value test results of Libya conflict are shown in table 5 . Based on the results, we get $-5,-1,0,1,2,3,6,7$ and 10 are significant change points in the event window at the confidence level of $95 \%$ and $99 \%$. There are more significant date because we select a relatively short period in this section. But it can reflect the influence about the conflict in Libya, we can draw a periodic result. Namely, we believe that Libya conflict passed violent information to the crude oil market at the possibility of $99 \%$. And the conflict had a significant impact on crude oil price when it happened. It can be seen from figure 5. The influence lasted for at least three days, and the significant effect on the fourth day is not obvious. The continuous influence of abnormal rate of return gradually reduced, until it almost disappeared.

Next, we analyze the impact of IEA release of crude oil reserves on international market price in June 23rd. When we set the announced date as the event day, the estimation window is from January 5, 2011 to June 1, 2011 and the event window is 
from June 2, 2011 to July 15, 2011. There are 15 days' data before and after the event day. We calculate and estimate mean and variance of the rate of returns in the window, for parameter estimation. The average value and the variance separately are 0.216 and 3.35. The rate of return model can be expressed as the following equation, $e_{t}$ is normally distributed.

$$
R_{t}=0.216+e_{t}, \quad e_{t} \sim N(0,3.35)
$$

The results of Libya conflict strategic reserves event window $\mathrm{P}$ value test is shown in table 6 . According to the results shown in the table, -6, 0, 1 and 4 were significant at the confidence level of $95 \%$. But -6 and 0 were significant at the level of 99\%. It, indicates that the release of strategic crude oil reserve on June 23rd had an impact on crude oil price at the reliability of $99 \%$. Combined with the results in figure 6, the impact of IEA third strategic oil reserve releases on oil price lasted for 3 days. Moreover, the significant effect on the third day is not obvious and there were no effect on the abnormal rate of return.

\subsection{Results of Comparison}

Compare the impact of Hurricane Katrina in 2005 and Libya conflict in 2011 on crude oil price and the results are shown in table7.

Two events separately belong to different types. The impact on crude oil abnormal rate of return by natural disaster in 2005 was relatively less than the regional conflict in 2011 in the same event window of 21 days for the reason that the natural disaster used strategic oil reserves on the third day of the incident. Even though the oil production was higher and the losses were greater in the area of natural 
disaster, the influence duration was not long. However, the regional conflict had longer influence because of interest disputes or escalation after the outbreak of the war. Because two disasters use the strategic petroleum reserves, we will analyze the influence of IEA's three times oil reserves release in the history.

According to our analysis and table 8 , we can conclude that the three times strategic petroleum reserves release inhibitory effect of crude oil price of was gradually reduced on the event day. For the first time, the effect of alleviating price rising by Gulf War was obvious and the oil price was stable like before later. The effect of the second release began to decrease and the oil price continued to rise. The effect of short-term shocks by the third release was less than the second and the price of crude oil rose quickly. The influence duration of inhibiting crude oil price rising was also getting shorter and shorter.

The proportion of the releases of reserves in current consumption was gradually decreased. Namely, the share of increased supply was gradually reduced relative to demand. Of course, the amount of interruption caused by the event was also fewer and fewer. The impact of strategic oil reserves on inhibiting crude oil price rising was getting less and less. It mainly is following two reasons:

(1) Supply and demand pattern in world oil market has a large change. During the Gulf War, supply exceeded demand in international crude oil market. During the second time, there was nearly a state of balance between supply and demand, so the effect was weaker than the first time. During the third time of Libyan war, demand exceeds supply. The surplus production capacity had showed a trend of decline and 
concentrated in the Middle East. So the effect of reducing was more obvious. This suggestion that the strategic petroleum reserves in a state of oversupply can play better role than other situations.

(2)The political situation in 2011 was chaotic, and the reason for conflict was domestic economic problems. Low price of crude oil will stimulate the contradiction. So the less effect of using strategic reserves was partly for the unclear situation in conflict area and the potential effect of resisting. With the financialization of crude oil, speculation has more influence on crude oil price than other emergencies. So we cannot exclude speculation from the reasons of crude oil price rapid rising in the third release. Finally, there had existed a situation of international crude oil price declining during the third release. Moreover, the increased release of supply exceeds Libya Conflict's 1.6 million barrels / day. It may indicate a tricky intention.

\section{Conclusion}

With continued occurrence of emergency, it has more and more important influence on fluctuations of crude oil price and economic. According to the analysis of emergencies and strategic petroleum reserves releases on crude oil prices above, the following conclusions can be obtained:

(1)Emergency and strategic reserve can cause short-term fluctuations of crude oil price. Emergency can cause changes of crude oil price and even bring about structural adjustment. Finally, international crude oil price do not return to the past level while strategic oil can effectively inhibiting price rising. In the process of forecasting crude oil price, we must pay more attention to emergencies. Hence, analysis of crude oil 
price must simultaneously consider emergencies and strategic petroleum reserves.

(2) Different types and stages of Emergency will have various influences on fluctuations of crude oil price. The impact of natural disaster is less than conflict and has limited subsequent influence. Therefore, we should consider the specific event and the overall economic environment under consideration.

(3)Strategic oil reserves releases are effective in alleviating crude oil price fluctuation by emergency. But the role of stabilizing crude oil price gradually weakens on considering the international crude oil supply and demand background change. The effect of alleviating crude oil prices rising by Gulf War in the first time was the most obvious, and then the degree and duration of influence by emergency presented a gradual weakening trend.

\section{Acknowledgments}

This work is partially supported by grants from the National Science Foundation of China (NSFC nos. U1333115, 71373188, 71101060, 90924024, 91224001, 81372804,71231007 and 71101060) and, the Fundamental Research Funds for the Central Universities(No.1101012), Post-1970 Young Scholars in Humanities and Social Sciences from Wuhan University, Training Program of High Level International Journal Articles in Humanities and Social Sciences from Wuhan University, the Huibei province Science Foundation(2011CDB191), and the Central University Basic Science Research Fund (2012QN188).

\section{References}

[1] Aydin G. Production modeling in the oil and natural gas industry: An 
application of trend analysis[J]. Petroleum Science and Technology, 2015, 32(5):555-564.

[2] Zhang X, Lai K K, Wang S Y. A new approach for crude oil price analysis based on Empirical Mode Decomposition[J]. Energy Economics, 30(3):905-918.

[3] Xun Zhang, lean Yu, Jianqiang Li, etc. Estimating the effects of extreme events to crude oil price [J]. System Engineering Theory and Practice, 2009, 31 (5):768-778.

[4] Longwell, J. H. The future of the oil and gas industry: past approaches, new challenges[J]. World Energy, 2002, 5: 100-104.

[5] Utgikar PV, Scott PJ. Energy forecasting: predictions, reality and analysis of causes of error[J]. Energy Policy, 2006, 34: 3087-3092.

[6] Aydin G. Modeling of energy consumption based on economic and demographic factors: The case of Turkey with projections[J]. Renewable and Sustainable Energy Reviews, 2014, 35: 382-389

[7] Say PN, Yücel M. Energy consumption and $\mathrm{CO} 2$ emissions in Turkey: empirical analysis and future projection based on an economic growth[J]. Energy Policy, 2006, 34: 3870-3876.

[8] Azadeh A, Tarverdian S. Integration of genetic algorithm, computer simulation and design of experiments for forecasting electrical energy consumption $[\mathrm{J}]$. Energy Policy, 2007, 35: 5229-5241.

[9] Holditch, A. S., and Chianelli, R. R. Factors that will influence oil and gas supply and demand in the 21st century[J]. MRS Bull. 2008, 33:317-323. 
[10] Feng YY, Zhang XL. Scenario analysis of urban energy saving and carbon abatement policies: a case study of Beijing city[J]. China Procedia Environ Sci, 2012, 13: $632-644$

[11] Aydin G. The Development and validation of regression models to predict energy-related CO2 emissions in Turkey[J]. Energy Sources Part B: Economics, Planning, and Policy, 2015, 10 (2): 176-182.

[12] Aydin G. The modeling of coal related $\mathrm{CO} 2$ emissions and projections into future planning[J]. Energy Sources Part A: Recovery, Utilization, and Environmental Effects, 2014, 36 (2): 191-201.

[13] TuoJi, Yanbin Sun. An empirical analysis on the influencing factors of international oil price fluctuations [J]. Journal of Industrial Technological Economics, 2001, 9:155-160.

[14] Xiucheng Dong, Wenhong Cao. An analysis of varieties of uncertain factors in forecasting international oil price $[\mathrm{J}]$. Journal of the University of Petroleum (Edition of Social Sciences), 2000, 16 (2):6-10.

[15] Yan Fang, Mei Li. An empirical analysis on the influencing factors of international oil price fluctuations [J]. Price Theory and Practice, 2012, 61-62.

[16] Minglei Zhou. Intervention Analysis with time -series to the world Crude oil Price[J]. Mathematics in Practice and Theory, 2004 (8), 12-18.

[17] Shuping Wang, Jinshan Li, Jianping Li, etc. An analysis about effects of war's phases on international oil price [J]. Chinese Journal of Management Science, $2005,13,201-205$ 
[18] Shu-ping Wang, Yu Chen, Yujing Jin. Analysis about the impact of emergencies on international oil price [J]. Mathematics in Practice and Theory, 2009 (9):88-92.

[19] Jianling Jiao, Junling Zhang, Yiming Wei. Research on the value of petroleum reserve based on supply chain [J]. Journal of Management Science in China, 2011, 14 (2): 53-60.

[20] Xinxin Wang. Surveying the development of China's oil reserves and the countermeasure analysis [J]. Technoeconomics and Management Research, 2013 (2): 102-106.

[21] Hui Li, Renjin Sun, Kangyin Dong. The U.S. strategic petroleum reserve margin strategy analysis and implications to our country [J]. Price Theory and Practice, 2014 (11):56-57.

[22] Yao Wang, Jing Lv. Study on the optimal scale of Chinese petroleum security reserve [J]. Safety and Environmental Engineering, 2014, 21 (2): 130-134.

[23] Pan Wei, Yu Lean, Wang Shouyang, et al, A fuzzy multi-objective model for provider selection in data communication services with different QoS levels, International Journal of Production Economics, 2014, 147:689-696.

[24] Pan Wei, Wang Xianjia, Zhong Yong-guang, et al, A fuzzy multi-objective model for capacity allocation and pricing policy of provider in data communication service with different QoS levels, International Journal of Systems Science, 2012, 43(6):1054-1063.

[25] Bai J, Perron P. Computation and analysis of multiple structural change 
models[J]. Journal of Applied Econometrics， 2003， 18(1):1-22.

Table 1: WTI descriptive statistics

\begin{tabular}{|l|l|l|l|l|}
\hline $\begin{array}{l}\text { Descriptive } \\
\text { Object }\end{array}$ & mean & maximum & Minimum & count \\
\hline WTI & 43.97 & 133.88 & 11.35 & 333 \\
\hline
\end{tabular}

Table 2: Breakpoints test table

\begin{tabular}{|c|c|c|c|c|c|c|c|}
\hline $\begin{array}{l}\text { The } \\
\text { number } \\
\text { of } \\
\text { breakpoi } \\
\text { nts }\end{array}$ & \multicolumn{5}{|c|}{ The time of breakpoints } & $\begin{array}{l}\text { RSS } \\
\text { standards }\end{array}$ & $\begin{array}{l}\text { BIC } \\
\text { standards }\end{array}$ \\
\hline 0 & & & & & & $\begin{array}{l}323140.8 \\
06\end{array}$ & 3246.904 \\
\hline 1 & & & & $\begin{array}{l}2005 \\
(5)\end{array}$ & & 57414.45 & 2683.165 \\
\hline 2 & & & & $\begin{array}{l}2007 \\
(8)\end{array}$ & & $\begin{array}{l}44336.84 \\
7\end{array}$ & 2608.708 \\
\hline 3 & & & $\begin{array}{l}1999 \\
(11)\end{array}$ & $\begin{array}{l}2005 \\
(5)\end{array}$ & $\begin{array}{l}2010 \\
(10)\end{array}$ & $\begin{array}{l}38273.43 \\
2\end{array}$ & 2571.353 \\
\hline 4 & 1993(5) & & $\begin{array}{l}1999 \\
(11)\end{array}$ & $\begin{array}{l}2005(5 \\
)\end{array}$ & $\begin{array}{l}2010 \\
(10)\end{array}$ & $\begin{array}{l}38146.13 \\
8\end{array}$ & 2581.860 \\
\hline 5 & $\begin{array}{l}1991 \\
(10)\end{array}$ & $\begin{array}{r}1995 \\
(11) \\
\end{array}$ & $\begin{array}{l}1999 \\
(12)\end{array}$ & $\begin{array}{l}2005(5 \\
)\end{array}$ & $\begin{array}{l}2010 \\
(10)\end{array}$ & $\begin{array}{l}38213.92 \\
1\end{array}$ & 2594.067 \\
\hline Brent & & & $\begin{array}{l}1999 \\
(10)\end{array}$ & $\begin{array}{l}2005 \\
(5)\end{array}$ & $\begin{array}{l}2010 \\
(11)\end{array}$ & $\begin{array}{l}39701.17 \\
0\end{array}$ & 2583.549 \\
\hline
\end{tabular}

Table 3: the first strategic oil reserve release event window $P$ value test

\begin{tabular}{|c|c|c|c|c|c|}
\hline-30 & Dec 04, 1990 & 0.91496055 & 1 & Jan 18,1991 & 0.628587 \\
\hline-29 & Dec 05, 1990 & 0.639703 & 2 & Jan 21, 1991 & 0.634886 \\
\hline-28 & Dec 06, 1990 & 0.81587306 & 3 & Jan 22, 1991 & 0.364116 \\
\hline-27 & Dec 07, 1990 & 0.97004327 & 4 & Jan 23, 1991 & 0.801124 \\
\hline-26 & Dec 10,1990 & 0.9294966 & 5 & Jan 24, 1991 & 0.699753 \\
\hline-25 & Dec 11,1990 & 0.86433901 & 6 & Jan 25, 1991 & 0.673483 \\
\hline-24 & Dec 12,1990 & 0.73810727 & 7 & Jan 28, 1991 & 0.345378 \\
\hline-23 & Dec 13,1990 & 0.78953744 & 8 & Jan 29, 1991 & 0.849799 \\
\hline-22 & Dec 14,1990 & 0.99203765 & 9 & Jan 30, 1991 & 0.819187 \\
\hline-21 & Dec 17,1990 & 0.9236344 & 10 & Jan 31, 1991 & 0.82178 \\
\hline-20 & Dec 18,1990 & 0.87814716 & 11 & Feb 01, 1991 & 0.839822 \\
\hline-19 & Dec 19,1990 & 0.94474051 & 12 & Feb 04, 1991 & 0.953277 \\
\hline-18 & Dec 20, 1990 & 0.83522108 & 13 & Feb 05, 1991 & 0.845472 \\
\hline
\end{tabular}




\begin{tabular}{|c|c|c|c|c|c|}
\hline-17 & Dec 21,1990 & 0.89704476 & 14 & Feb 06, 1991 & 0.827829 \\
\hline-16 & Dec 24, 1990 & 0.95268149 & 15 & Feb 07, 1991 & 0.941106 \\
\hline-15 & Dec 26, 1990 & 0.94411418 & 16 & Feb 08, 1991 & 0.911782 \\
\hline-14 & Dec 27, 1990 & 0.90049007 & 17 & Feb 11, 1991 & 0.864829 \\
\hline-13 & Dec 28, 1990 & 0.90008095 & 18 & Feb 12, 1991 & 0.942508 \\
\hline-12 & Dec 31, 1990 & 0.85308328 & 19 & Feb 13, 1991 & 0.884876 \\
\hline-11 & $\operatorname{Jan} 02,1991$ & 0.61906263 & 20 & Feb 14, 1991 & 0.947336 \\
\hline-10 & Jan 03, 1991 & 0.79393715 & 21 & Feb 15,1991 & 0.619837 \\
\hline-9 & Jan 04, 1991 & 0.82666147 & 22 & Feb 18, 1991 & 0.978084 \\
\hline-8 & Jan 07, 1991 & 0.56521919 & 23 & Feb 19, 1991 & 0.811533 \\
\hline-7 & Jan 08, 1991 & 0.97366756 & 24 & Feb 20, 1991 & 0.995669 \\
\hline-6 & Jan 09, 1991 & 0.92681195 & 25 & Feb 21, 1991 & 0.541682 \\
\hline-5 & Jan 10, 1991 & 0.89279447 & 26 & Feb 22, 1991 & 0.678242 \\
\hline-4 & Jan 11,1991 & 0.95503907 & 27 & Feb 25, 1991 & 0.978084 \\
\hline-3 & Jan 14,1991 & 0.55232656 & 28 & Feb 26, 1991 & 0.718906 \\
\hline-2 & Jan 15,1991 & 0.98347804 & 29 & Feb 27, 1991 & 0.867566 \\
\hline-1 & Jan 16, 1991 & 0.70791476 & 30 & Feb 28, 1991 & 0.952981 \\
\hline 0 & Jan 17,1991 & 0.00655125 & & & \\
\hline
\end{tabular}

Table 4: Hurricane and the second strategic reserve release event window $P$ value test

\begin{tabular}{|r|r|r|r|r|r|}
\hline-10 & Aug 16, 2005 & 0.750066876 & 1 & Aug 31, 2005 & 0.173988391 \\
\hline-9 & Aug 17, 2005 & $\mathbf{0 . 0 0 3 7 2 9 0 1 3}$ & 2 & Sep 01, 2005 & 0.584378776 \\
\hline-8 & Aug 18, 2005 & 0.95885709 & 3 & Sep 02, 2005 & $\mathbf{0 . 0 1 0 5 9 5 0 0 4}$ \\
\hline-7 & Aug 19, 2005 & 0.086344634 & 4 & Sep 06, 2005 & 0.220895114 \\
\hline-6 & Aug 22, 2005 & 0.785111172 & 5 & Sep 07, 2005 & 0.111330509 \\
\hline-5 & Aug 23, 2005 & 0.919290562 & 6 & Sep 08, 2005 & 0.862565554 \\
\hline-4 & Aug 24, 2005 & 0.334488127 & 7 & Sep 09, 2005 & 0.431302041 \\
\hline-3 & Aug 25, 2005 & 0.958249888 & 8 & Sep 12, 2005 & 0.266483335 \\
\hline-2 & Aug 26, 2005 & 0.171656019 & 9 & Sep 13, 2005 & 0.739479776 \\
\hline-1 & Aug 29, 2005 & 0.305567395 & 10 & Sep 14, 2005 & 0.088202699 \\
\hline 0 & Aug 30, 2005 & $\mathbf{0 . 0 4 4 6 1 7 0 3 2}$ & & & \\
\hline
\end{tabular}

Table 5: Libya conflict abnormal rate of returns event window $P$ value test

\begin{tabular}{|r|r|r|r|r|r|}
\hline-10 & Feb 07, 2011 & 0.572364 & 1 & Feb 23, 2011 & $\mathbf{0 . 0 0 0 3}$ \\
\hline-9 & Feb 08, 2011 & 0.381706 & 2 & Feb 24, 2011 & 3E-07 \\
\hline-8 & Feb 09, 2011 & 0.408665 & 3 & Feb 25, 2011 & 9E-05 \\
\hline-7 & Feb 10, 2011 & 0.756856 & 4 & Feb 28, 2011 & 0.601804 \\
\hline-6 & Feb 11, 2011 & 0.068155 & 5 & Mar 01, 2011 & 0.378057 \\
\hline-5 & Feb 14, 2011 & $\mathbf{2 . 0 3 E - 0 5}$ & 6 & Mar 02, 2011 & $\mathbf{3 . 0 2 E - 0 5}$ \\
\hline-4 & Feb 15, 2011 & 0.12372 & $\mathbf{7}$ & Mar 03, 2011 & $\mathbf{0 . 0 0 0 1 0 8}$ \\
\hline-3 & Feb 16, 2011 & 0.896831 & 8 & Mar 04, 2011 & 0.251223 \\
\hline
\end{tabular}




\begin{tabular}{|r|r|r|r|r|r|}
\hline-2 & Feb 17, 2011 & 0.673678 & 9 & Mar 07, 2011 & 0.565889 \\
\hline-1 & Feb 18, 2011 & $\mathbf{0 . 0 1 4 1 5 8}$ & 10 & Mar 08, 2011 & $\mathbf{2 . 6 9 E - 1 0}$ \\
\hline 0 & Feb 22, 2011 & $\mathbf{4 . 6 E - 1 0}$ & & & \\
\hline
\end{tabular}

Table 6: the results of Libya strategic reserves event window $P$ test

\begin{tabular}{|r|r|r|r|r|r|}
\hline-15 & Jun 02, 2011 & 0.275187 & 1 & Jun 24, 2011 & $\mathbf{0 . 0 3 6 9 7 5}$ \\
\hline-14 & Jun 03, 2011 & 0.777421 & 2 & Jun 27, 2011 & 0.798251 \\
\hline-13 & Jun 06, 2011 & 0.975024 & 3 & Jun 28, 2011 & 0.117828 \\
\hline-12 & Jun 07, 2011 & 0.800276 & 4 & Jun 29, 2011 & $\mathbf{0 . 0 4 4 0 5 8}$ \\
\hline-11 & Jun 08, 2011 & 0.2986 & 5 & Jun 30, 2011 & 0.990648 \\
\hline-10 & Jun 09, 2011 & 0.526157 & 6 & Jul 01, 2011 & 0.249512 \\
\hline-9 & Jun 10, 2011 & 0.452047 & 7 & Jul 05, 2011 & 0.090893 \\
\hline-8 & Jun 13, 2011 & 0.446391 & 8 & Jul 06, 2011 & 0.96028 \\
\hline-7 & Jun 14, 2011 & 0.841964 & 9 & Jul 07, 2011 & 0.061921 \\
\hline-6 & Jun 15, 2011 & $\mathbf{0 . 0 0 2 4 8 9}$ & 10 & Jul 08, 2011 & 0.896753 \\
\hline-5 & Jun 16, 2011 & 0.90502 & 11 & Jul 11, 2011 & 0.876606 \\
\hline-4 & Jun 17, 2011 & 0.530115 & 12 & Jul 12, 2011 & 0.900791 \\
\hline-3 & Jun 20,2011 & 0.346846 & 13 & Jul 13, 2011 & 0.668017 \\
\hline-2 & Jun 21, 2011 & 0.817126 & 14 & Jul 14, 2011 & 0.497647 \\
\hline-1 & Jun 22, 2011 & 0.48165 & 15 & Jul 15, 2011 & 0.828887 \\
\hline $\mathbf{0}$ & Jun 23, 2011 & $\mathbf{0 . 0 0 2 6 8}$ & & & \\
\hline
\end{tabular}

Table 7: comparison of the impact of emergencies

\begin{tabular}{|l|l|l|}
\hline emergency & Hurricane Katrina in 2005 & Libya conflict in 2011 \\
\hline type & Natural disaster & Regional conflict \\
\hline Impacts on the event day & 3.27 & 4.044 \\
\hline duration & 5 & 8 \\
\hline
\end{tabular}

Table 8: different effects of strategic petroleum reserves

\begin{tabular}{|l|l|l|l|}
\hline \multicolumn{1}{|c|}{$\begin{array}{c}\text { Events using } \\
\text { strategic reserves }\end{array}$} & Gulf war & Hurricane Katrina & Libyan conflict \\
\hline Types of events & regional conflict & natural disaster & regional conflict \\
\hline $\begin{array}{l}\text { The amount of } \\
\text { reliefs }\end{array}$ & 41.05 & 6.48 (USA+IEA) & 5.0 \\
\hline Influence duration & $>30$ days & $10-15$ days & $<6$ days \\
\hline
\end{tabular}




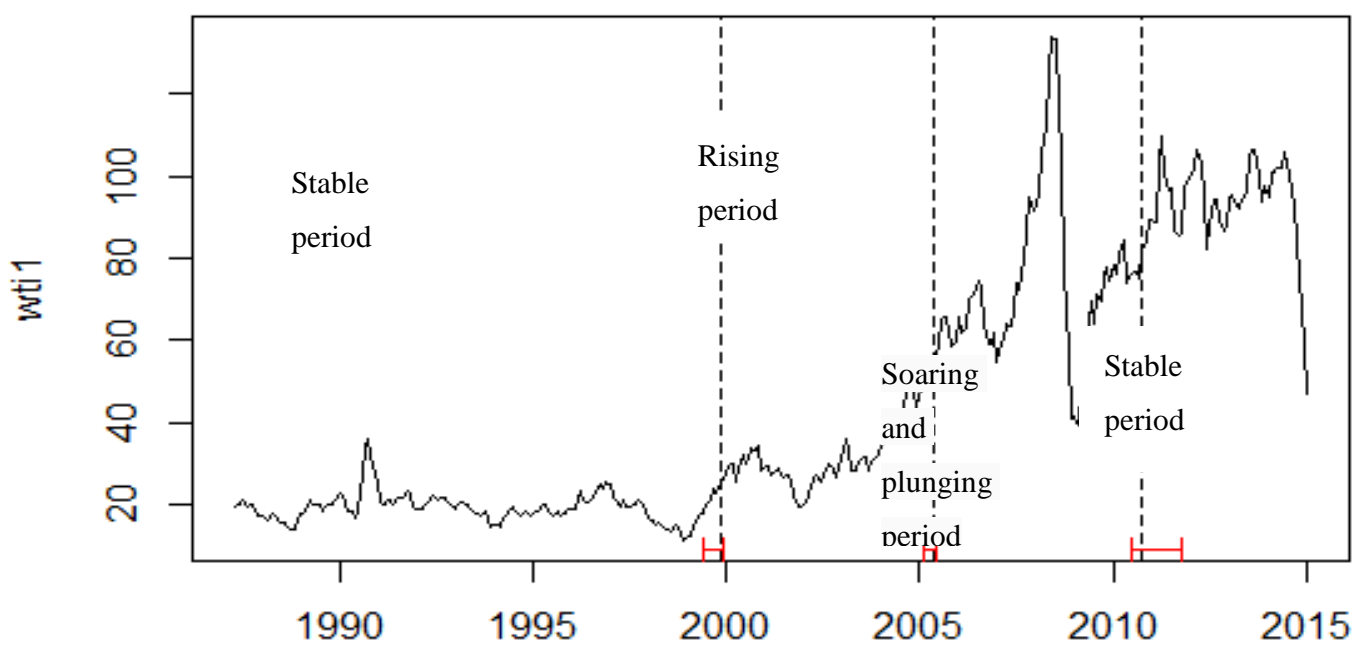

Figure 1: WTI structural breakpoints line mark

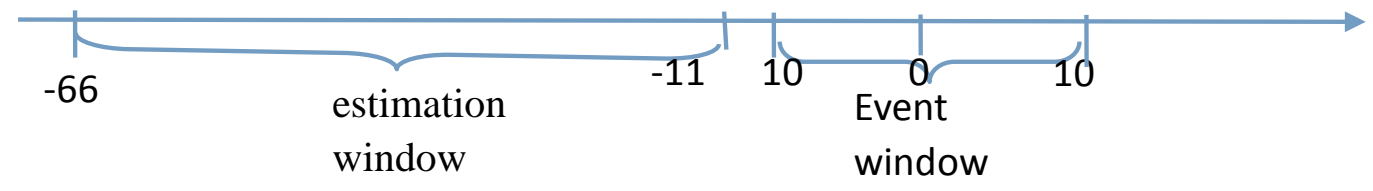

Figure 2 the division of estimation window and event window

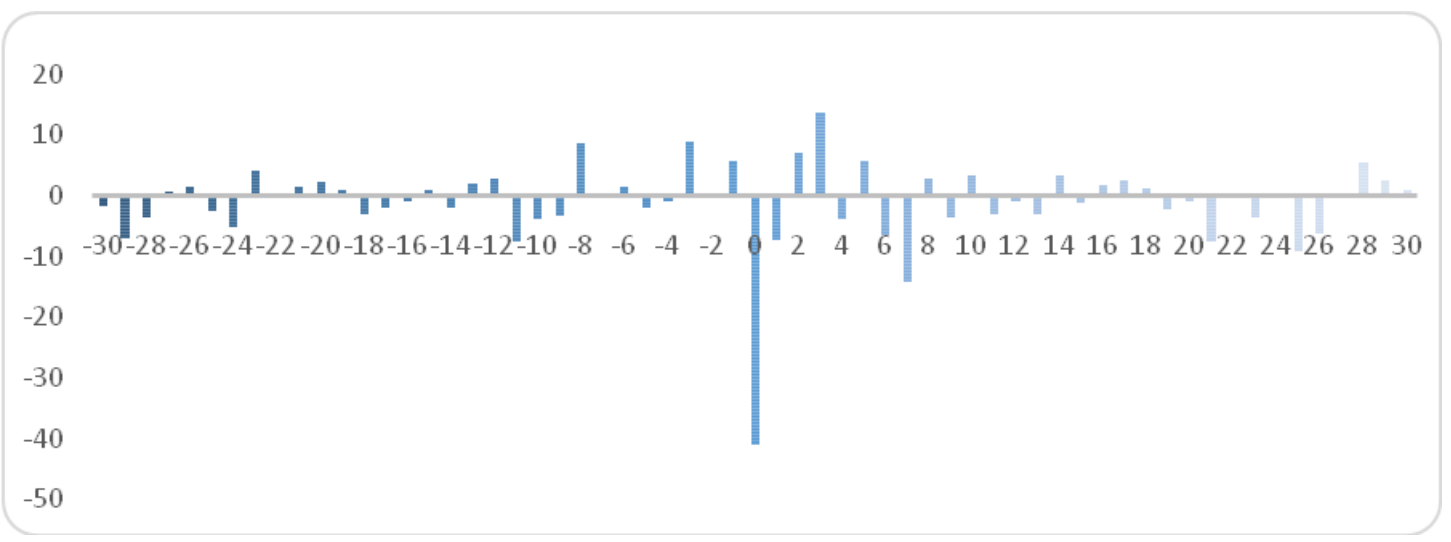

Figure 3: the abnormal income changes in the first strategic oil reserve release 


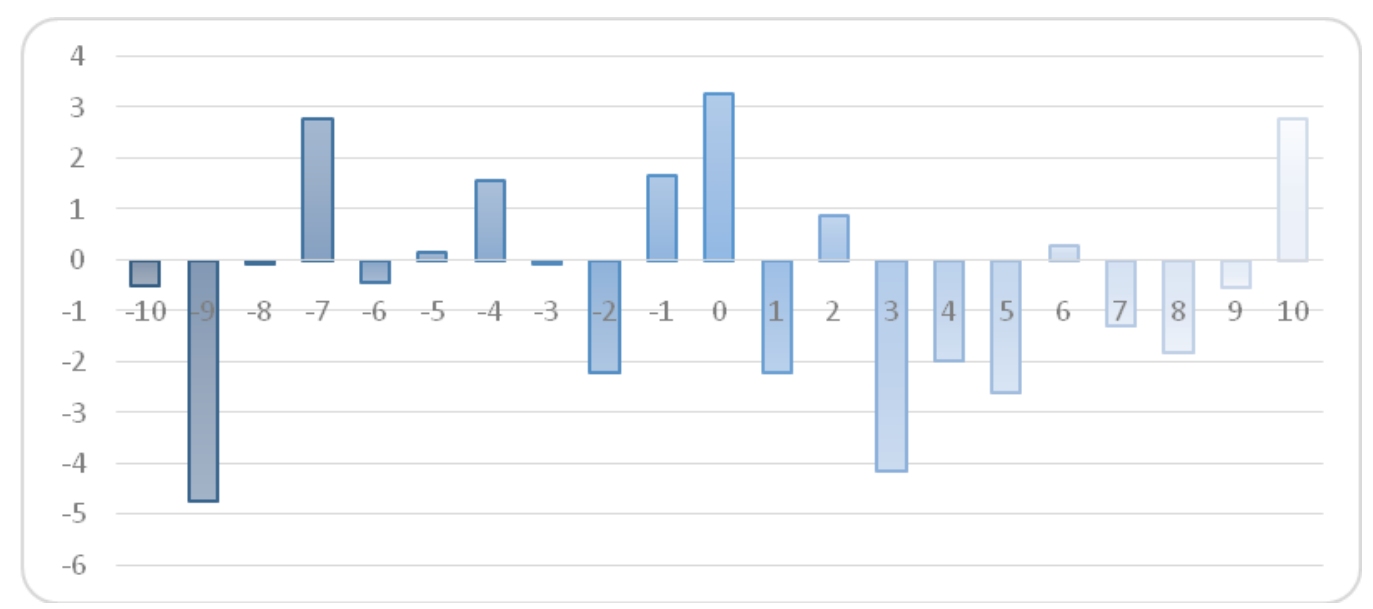

Figure 4: the abnormal rate of return changes in the hurricane and the second strategic reserve release

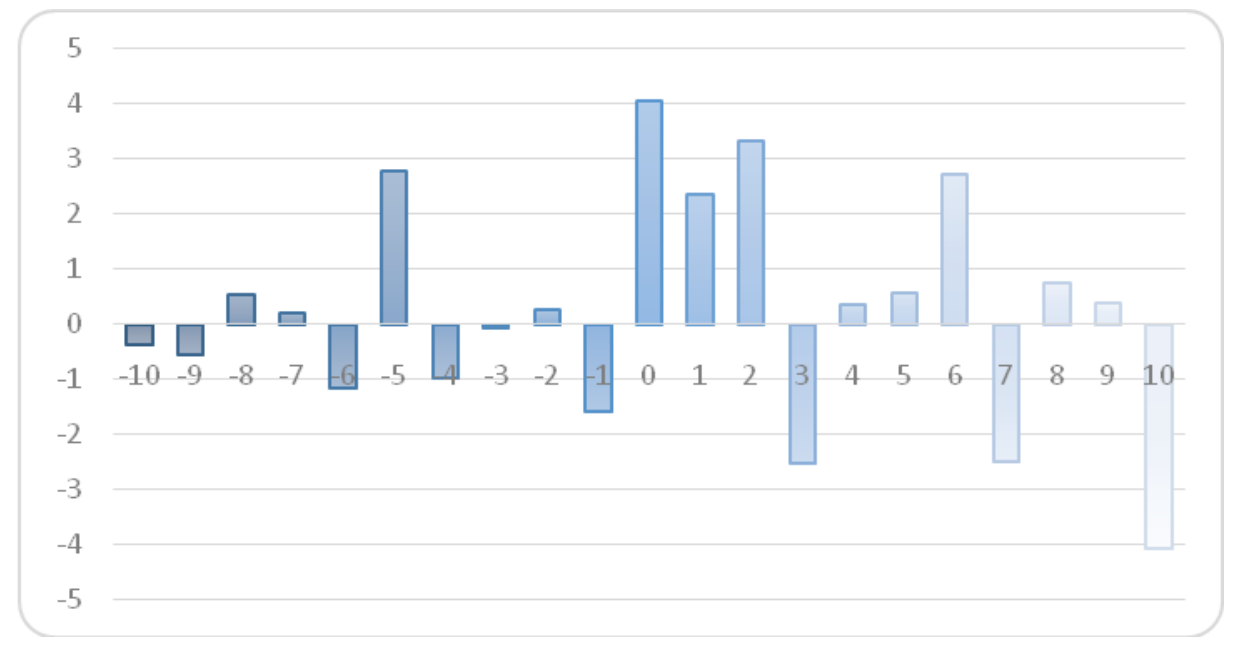

Figure 5: Libya Conflict event window abnormal rate of return changes

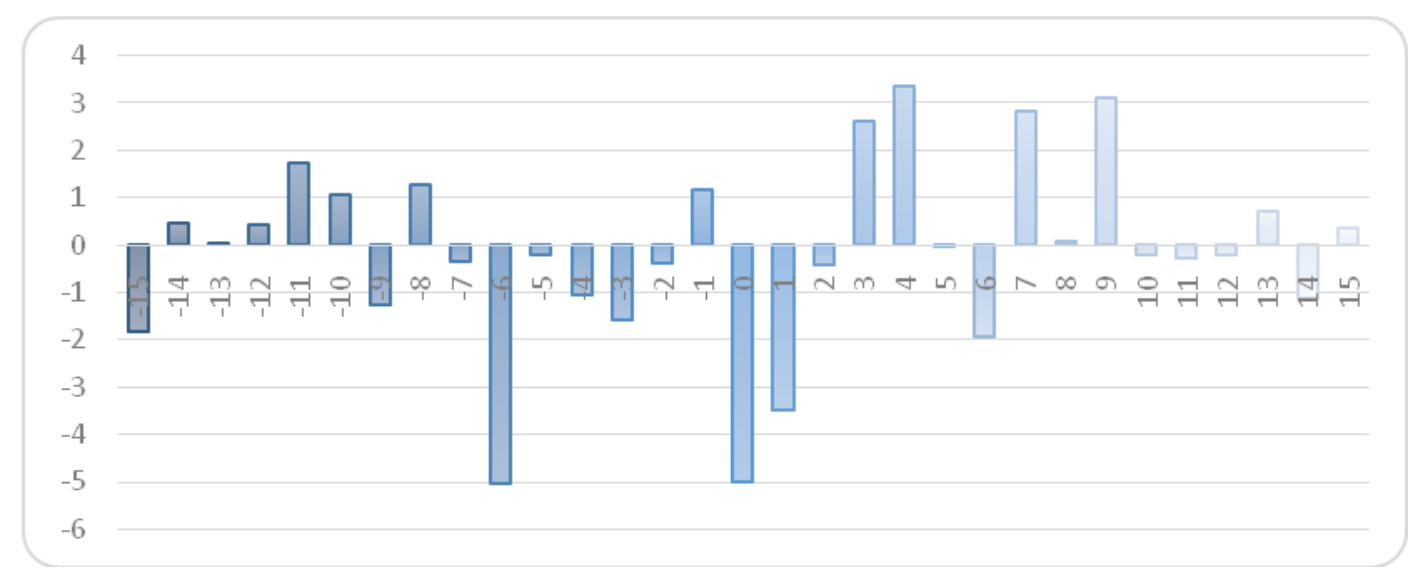

Figure 6: Libya strategic reserves abnormal rate of return changes 